\title{
Synthesis and Characterization 6-Hydroxy-4 - Metheyl -5 - Phenyla Zo Coumarins with Divalent Transition Metal Ions
}

\author{
Dalal .M. Ibrahim ${ }^{\text {A }}$, Juliana Jumal ${ }^{\mathrm{a}}$, Farah Wahida Harun ${ }^{\mathrm{b}}$ \\ Faculty of Science and Technology, Universiti Sains Islam Malaysia, 71800 Nilai, Malaysia.
}

\begin{abstract}
6-hydroxy-4metheyl-5-phenyl azo coumarin have been prepared and characterized by elemental analysis, infrared (IR), proton nuclear magnetic resonance $\left({ }^{I} \mathrm{H} N M R\right)$ and Mass spectra. The important infrared (IR) spectral bands corresponding to the active groups in the ligand and the solid complexes under investigation were studied. Also the important fragments in the ligand and the complexes were done using mass spectra and the main peaks were corresponding to the molecular weights of the ligand and complexes. The solid complexes have been synthesized and studied by elemental and as well as by IR, ${ }^{I} H$ NMR, mass spectra, molar conductance,. All of the prepared solid complexes behave as non-electrolytes in chloroform.

Keywords: Synthesis; Transition metal complexes; Spectroscopic; molar Conductance.
\end{abstract}

\section{Introduction}

Coumarin (2H-1-benzopyran-2-one), the parent molecule of coumarin derivatives, is the simplest compound of a large class of naturally occurring phenolic substances made of fused benzene and $\alpha$-pyrone rings [1]. The pharmacological and biochemical properties and therapeutic applications of simple coumarins depend upon the pattern of substitution [2].

Monohydroxy compounds containing coumarin nucleus have proved to be of great importance, introduction of azo group to such hydroxy coumarins increases its chelating tendency. From the structural point of view, these compounds were considered as metal indicators as they possess functional groups capable of chelate formation binding directly to the central metal ions. Synthesis of a series of 9 new azocoumarin dyes were reported. These dyes were obtained, confirmed and characterized [3]. The emission characteristics of some 8-(arylazo)-7-hydroxy-4-methylcoumarin have been studied [4]. The action of the coumarin-type drugs and related compounds is reviewed to their antagonistic effects. Twenty 3-pyridinyl, pyrimidinyl and pyrazolyl-4hydroxycoumarin derivatives were synthesized. The most prospective compounds were the 3-pyrazolyl-4hydroxy coumarin derivatives [5]. The cyclo addition reaction of unsymmetrically $\mathrm{N}$-substituted and $\mathrm{N}$ unsubstituted 1,3-oxazolium-5-olates with selected 3-substituted coumarins has been examined [6]. The synthesis of novel metal-free and zinc phthalocyanines with four 3-[(2-diethylamino)ethyl]-7-oxo-4methylcoumarin dye groups on the periphery were prepared [7]. A series of new fluorinated coumarins and 1azacoumarins were synthesized [8] and the effect of fluorine in the molecule on their anti-microbial, antiinflammatory and analgesic activities is discussed. Structural study of supramolecular photochemical $\beta$ cyclodextrin ( $\beta-C D)$-coumarin derivatives systems and the crystal structure of the $\beta$-CD-4,7-dimethylcoumarin complex has been determined [9]. Two new coumarin derivatives, 7-(diethylamino)-3-(pyridin-2-yl)coumarin (DAPC) and 3-(pyridin-2-yl)-benzo[5,6]coumarin (PBC) were synthesized [10]. A novel ligand, 7-(2,3dicyanophenoxy)-3-(2-chloro-4-fluorophenyl)coumarin was synthesized by the reaction of 3-(2-chloro-4fluorophenyl)-7-hydroxycoumarin with 1,2-dicyano-3-nitrobenzen in dry DMF as the solvent in the presence of $\mathrm{K}_{2} \mathrm{CO}_{3}$ as the base. The structures of the compounds were confirmed by elemental analysis, UV-vis, IR, MALDI-TOF mass and ${ }^{1} \mathrm{H}$ NMR spectra [11].

The aim of this work is to synthesize and examine some azocoumarins and their complexes with $\mathrm{Mn}(\mathrm{II}), \mathrm{Co}(\mathrm{II}), \mathrm{Ni}(\mathrm{II}), \mathrm{Cu}(\mathrm{II})$ and $\mathrm{Zn}(\mathrm{II})$ divalent transition metal ions. The solid complexes have been prepared and studied by elemental as well as by IR, ${ }^{1} \mathrm{H}$ NMR, , molar conductance, mass spectra.

\section{Experimental}

\section{Materials}

All chemicals used were of the highest purity grade from $\mathrm{BDH}$ used as received without further purification. These included manganese (II) chloride $\left(\mathrm{MnCl}_{2} \cdot 4 \mathrm{H}_{2} \mathrm{O}\right)$, cobalt (II) chloride $\left(\mathrm{CoCl}_{2} \cdot 6 \mathrm{H}_{2} \mathrm{O}\right)$, nickel (II) chloride $\left(\mathrm{NiCl}_{2} \cdot 6 \mathrm{H}_{2} \mathrm{O}\right)$, copper (II) chloride $\left(\mathrm{CuCl}_{2} \cdot 2 \mathrm{H}_{2} \mathrm{O}\right)$, zinc chloride $\left(\mathrm{ZnCl}_{2}\right)$, aniline, sodium hydroxide, ammonium hydroxide $\left(30 \% \mathrm{NH}_{3}\right)$, sodium chloride, silver nitrate $\left(\mathrm{AgNO}_{3}\right)$, sulphuric acid $\left(\mathrm{H}_{2} \mathrm{SO}_{4}\right)$, and hydrochloric acid $(37 \% \mathrm{HCl})$. The solvents used were ethanol, chloroform and Dimethylsulphoxide (DMSO). 


\section{Synthesis of 6-hydroxy-4-methyl coumarin}

6-Hydroxy-4-methylcoumarin was synthesized by adding equal molar quantities of Hydroquinone and ethylacetoacetate in presence of concentrated $\mathrm{H}_{2} \mathrm{SO}_{4} .43 \mathrm{ml}$ concentrated $\mathrm{H}_{2} \mathrm{SO}_{4}$ was placed in $100 \mathrm{ml}$ beaker surrounded by ice salt bath. When the temperature falls below $10{ }^{\circ} \mathrm{C}, 20 \mathrm{~g}$ of hydroquinone in $25 \mathrm{ml}$ of ethylacetoacetate was added dropwisely with constant stirring. The temperature is kept below $10{ }^{\circ} \mathrm{C}$ by means of an ice salt bath during the addition (5 hours). The reaction mixture is kept at room temperature for about 18 hours, and then poured with vigorous stirring into a mixture of crushed ice and water. The precipitate was collected by suction filtration and washed with water. The solid was dissolved in $300 \mathrm{ml}$ of $5 \% \mathrm{NaOH}$ solution, filtered and dilute (1:10) $\mathrm{H}_{2} \mathrm{SO}_{4}(110 \mathrm{ml})$ was added with vigorous stirring until the solution is acid to litmus. The crude 6-hydroxy-4-methylcoumarin was collected by filtration at the pump, washed with cold water, dried at $100{ }^{\circ} \mathrm{C}$, recrystallized form $25 \%$ ethanol. The structure was confirmed by its melting point $243{ }^{\circ} \mathrm{C}$.

\section{Synthesis of Ligand}

A well-stirred solution of aniline $(0.01$ mole in $40 \mathrm{ml}$ ethanol) and $20 \mathrm{ml}$ of $2 \mathrm{M} \mathrm{HCl}$ was cooled in an ice salt bath and diazotized with aqueous sodium nitrite solution $(20 \mathrm{ml}, 0.01$ mole $)$. The cooled $\left(0-5^{\circ} \mathrm{C}\right)$ diazonium solution was added slowly to a well-stirred solution of ( 0.01 mole) 6-hydroxy-4-methylcoumarin in $(100 \mathrm{ml})$ ethanol containing sodium hydroxide $(0.01 \mathrm{~mole})$. The products were filtered off and recrystallized from absolute ethanol [12]. Elemental analyses for the prepared azocoumarin dye was done. The results obtained were in good agreement with the calculated values. The prepared azocoumarin dye has the following structural formulae:<smiles>Cc1cc(=O)oc2ccc(O)c(/N=N\c3ccccc3)c12</smiles>

FIGURE ( 1) structural formulae of azocoumarin day

Table (I) shows the analytical data of the prepared azo coumarin.

\section{Synthesis of Solid Complexes}

The solid complexes were synthesized by mixing a hot alcoholic saturated solution of ( 0.001 mole of metal ion dissolved in hot ethanol) with the required amount of the ligand under investigation sufficient to form 1:1 (M:L) complexes. The $\mathrm{pH}$ of the solution was then maintained at a value of 6-7 by addition of dilute (1:10) ammonia solution [13]. The reaction mixture was heated on a steam bath with occasional stirring for $4 \mathrm{hrs,}$ and evaporated till dryness. The produced complexes were then dissolved in ethanol to remove unreacted species. It was then filtered off by suction and rewashed with ethanol till a colorless filtrate was obtained, suction, filtered and then finally kept in a vacuum desiccator. The metal content of the prepared solid complexes was determined [14].

\section{Apparatus}

Elemental analysis Elemental analysis was performed in chemistry department of universiti kebangsaan malyasia .

FTIR spectra The IR spectra were recorded on fourier transform infra red spectrophotometer (FT-IR) varian 3100 excilabur in Faculty of Science and Technology USIM.

H NMR spectra The HNMR spectra were measured by using $400 \mathrm{MHz}$ spectrophotometer the solvent was (DMSO). The spectra were extended from (0-16) in technical services and metrology advisory section national metrology laboratory sirim berhad.

Mass spectra Mass spectra of the azocoumarins and some of their complexes were carried out using micrOTOF-Q 86 direct infuse+ve.m in universiti kebangsaan malyasia .

Molar conductance of the solid complexes in chloroform was measured using a conductivity meter type ((inolab digital conductivity meter). 


\section{Results And Discussion}

The solid complexes of $\mathrm{Mn}(\mathrm{II}), \mathrm{Co}(\mathrm{II}), \mathrm{Ni}(\mathrm{II}), \mathrm{Cu}(\mathrm{II})$ and $\mathrm{Zn}(\mathrm{II})$ metal ions with the investigated ligand have been synthesized as described in the experimental section.

Elemental analysis: data are shown in Table (II).

Infrared spectral :data and band assignments of the investigated ligand is shown in Table III. The IR spectra and the bands frequencies data shows the presence of a broad band at $3398 \mathrm{~cm}^{-1}$ which corresponds to the stretching vibration of the $\mathrm{OH}$ group of the ligand under investigation. The IR spectra of the investigated ligand show the $-\mathrm{C}=\mathrm{C}$-bands at $1525 \mathrm{~cm}^{-1}$. The bands in the $3000 \mathrm{~cm}^{-1}$ region are due to Ar-H stretching vibration while those appeared in the $1168 \mathrm{~cm}^{-1}$ region is due to aliphatic C-H stretching vibration. The $\gamma_{\mathrm{CH}}$ of the aromatic rings is observed at $899 \mathrm{~cm}^{-1}$. The number and shape of these bands depends on the position and the type of substituent present. The bands appearing in the IR spectra of the ligand at $1250 \mathrm{~cm}^{-1}$ is assigned to the stretching vibration of C-N and that at $1450 \mathrm{~cm}^{-1}$ is assigned to the stretching vibration of $\mathrm{N}=\mathrm{N}$ [15]. The band appearing at $1600 \mathrm{~cm}^{-1}$ is assigned to the stretching vibration of $\mathrm{C}=\mathrm{O}$ group.

The infrared spectra: of the solid complexes display interesting changes which may give a reasonable idea about the structure of these complexes. However, if these changes are interpreted in relation to elemental analysis and the results mass spectra, the picture of the solid complexes may be clarified. In the infrared spectra of the complexes which are shown in Tables IV and , the band observed at $1450 \mathrm{~cm}^{-1}$ assigned to ${ }_{\mathrm{N}=\mathrm{N}}^{\mathrm{v}}$ in the free ligand is shifted to the lower wave number on complex formation within the range $1382-1400 \mathrm{~cm}^{-1}$ indicating that it is a center of complexation. In the complexes, the band observed within the range 3585-3600 assigned to $\mathrm{v}_{\mathrm{O}-\mathrm{H}}$ of water of coordination and water of hydration, the band observed in the range $1670-1683 \mathrm{~cm}^{-1}$ assigned to ${ }_{\mathrm{C}=\mathrm{O}},{ }_{\mathrm{C}=\mathrm{C}}$ in the range $1550-1650 \mathrm{~cm}^{-1}$ and the band observed in the range $1198-1199 \mathrm{~cm}^{-1}$ corresponding to ${ }_{\mathrm{C}-\mathrm{O}}$ are shifted to lower wave number due to complexation. The spectra of metal complexes exhibit bands in the ranges 799-814 which may assigned ${ }^{\gamma} \mathrm{OH}$. In other words, these bands are possibly due to the formation of coordination and covalent bonds between the donor atoms ( $\mathrm{N}$ and $\mathrm{O}$ ) and the central metal ion.

${ }^{1} \mathrm{H}$ NMR spectra: of the investigated ligand (L and $\mathrm{Ni}(\mathrm{II})$ complexes were recorded in DMSO as a solvent . The chemical shift $(\delta)$ values of the different types of protons in the investigated ligands $(\mathrm{L})$ is reported in Table V. The ${ }^{1} \mathrm{H}$ NMR spectra of the investigated ligand L in DMSO exhibits a sharp signal at $12.44 \mathrm{ppm}$. This signal is assigned to the protons of the $\mathrm{OH}$ group. The aliphatic protons of the methyl groups of the pyrone ring appeared at $2.1 \mathrm{ppm}$. The signals observed at 7.42-7.39 ppm are assigned to the protons of the aromatic ring [16] while that observed at $7.14 \mathrm{ppm}$ are assigned to the proton of the pyrone ring [16].

For Ni-L, complexe, the disappearance of the signal observed at $12.44 \mathrm{ppm}$ in the free ligand indicates the deprotonation and involvement of the $\mathrm{OH}$ group in complexation. Coordinated water molecules were observed in the region 2.90 and $\mathrm{ppm}$. All of the other signals observed in the free ligand still present with some upfield shift which may be due to complexation.

Mass spectral studies of the investigated ligand and some of their complexes permits the elucidation of molecular weight. Mass spectroscopy has proved extremely valuable for the determination of accurate molecular weights, obtaining molecular formulae, ionization potentials and bond strengths . The observed peak at $\mathrm{m} / \mathrm{z} 277$ (calculated 280) represents the molecular ion peak of ligand. The fragmentation pattern of this ligand can be regarded as general scheme showing the main fragmentation paths involved.

The mass spectra of some complexes were recorded and their molecular ion peaks confirm the suggested formulae of these complexes. For complexes of ligand with $\mathrm{Zn}(1: 1) \mathrm{m} / \mathrm{z} 468$ (calculated 482).

The molar conductivities of the solid complexes were measured for complexes in chloroform and are found in the range of $9.3-26.5 \mathrm{ohm}^{-1} \mathrm{~cm}^{2} \mathrm{~mol}^{-1}$. These values were measurably small for the ionic complexes of the divalent metal ions. These low conductivity values may be attributed to the presence of chloride ions in the coordination sphere rather than ionic association to the metal ions during complex formation and also no white precipitate is formed by the addition of $\mathrm{AgNO}_{3}$. This directly supports the fact that all of the investigated complexes are non-ionic or non electrolytes in nature [17]. The conductivity values for all of the investigated complexes are listed in Tables II .

Based on the results of elemental analysis, IR, ${ }^{1} \mathrm{H}$ NMR, mass spectra, for the investigated ligands and, the $1: 1$ complexes are isolated as shown in Figure (2). 
<smiles>[H][Y9]([H])([O-])COc1ccc2oc(=O)cc(C)c2c1N=Nc1ccccc1</smiles>

$\oplus$

FIGURE ( 2) The proposed structures of the metal complexes

\section{Conclusion}

From elemental analysis, FTIR spectral data, ${ }^{1} \mathrm{H}$ NMR, mass spectral data, for the investigated ligand , the $1: 1$ complexes are isolated and one can conclude that:

(I)- The synthesized 6-hydroxy-4metheyl-5-phenyl azo coumarin complexes show that the structure of the complexes are formed through the deprotonation of the $\mathrm{OH}$ group in the aromatic ring and coordination of the nitrogen atom of the azo group in ligand

(II)- The ${ }^{1} \mathrm{H}$ NMR spectra of the ligands and their Ni(II) complexes are obtained and correlated, The proton of the $\mathrm{OH}$ group disappeared upon complexation.

(III) -The molar conductance shows that all of the complexes are neutral or non-electrolytes in nature.

\section{References}

[1] G. J. Keating, and R. O'Kennedy, In The chemistry and occurrence of coumarins, R.O'Kennedy and R. D. Thornes Eds., John Wiley \& Sons West Sussex, England, p. 23-64, 1997.

[2] I. Kostova, Curr. Med. Chem. - Anti-Cancer Agents, 5, 29 (2005).

[3] E. G. H. Shahinian, I. Haiduc and I. Sebe, UPB Sci. Bull., Series B: Chem. Mater. Sci, 73, 153 (2011).

[4] A. L. El-Ansary, E. M. Ebeid and M. M. Omar, Spectrochim. Acta, Part A, 43, 709 (1987).

[5] O. M. Abdelhafez, K. M. Amin, R. Z. Batran, T. J. Maher, S. A. Nada and S. Sethumadhavan, Bioorg. and Med. Chem., 18, 3371 (2010).

[6] M. Cordaro, G. Grassi, F. Risitano and A. Scala, Tetrahedron, 66, 2713 (2010).

[7] H. Çakici, A. A. Esenpinar and M. Bulut, Polyhedron, 27, 3625 (2008).

[8] R. G. Kalkhambkar, G. M. Kulkarni, C. M. Kamanavalli, N. Premkumar, S. M. B. Asdaq and C. M. Sun, Eur. J. Med. Chem., 43, 2178 (2008)

[9] T. J. Brett, J. M. Alexander and J. J. Stezowski, J. Chem. Soc., Perkin Trans. 2, 1095 (2000).

[10] T. Yu, S. Yang, Y. Zhao, H. Zhang, X. Han, D. Fan,Y. Qiu and L. Chen, J. Photochem. and Photobiol. A, Chemistry, 214, 92 (2010).

[11] A. Alemdar, A. R. Özkaya and M. Bulut, Synth. Met., 160, 1556 (2010).

[12] A. Z. El-Sonbati, R. M. Issa and A. M. Abd El-Gawad, Spectrochim. Acta, Part A, 68 (2007) 134.

[13] S. A. Abdel-Latif, H. B. Hassib and Y. M. Issa, Spectrochim. Acta, Part A, 67 (2007) 950.

[14] A. M. G. Macdonald and P. Sirichanya, Microchem. J., 14, 199 (1969).

[15] A. A. A. Emara, Synth. React. Inorg. Met-org, Chem., 29, 87 (1999).

[16] O. E. Sherif, Omar M. M. and Y. M. Issa, J. Therm. Anal., 39, 735 (1993).

[17] T. M. A. Ismail, J. Coord. Chem., 59, 255 (2006).

TABLE I Analytical data and yield \% for the investigated ligand.

\begin{tabular}{|c|c|c|c|c|c|c|c|}
\hline & & & & & & $\begin{array}{l}\text { Calcd. } \\
\text { Found } \\
\end{array}$ & \\
\hline $\begin{array}{l}\text { Liga } \\
\text { nd }\end{array}$ & $\begin{array}{l}\text { Tentative } \\
\text { formula }\end{array}$ & Color & M. wt & $\begin{array}{l}\text { Yiel } \\
\mathrm{d} \%\end{array}$ & $\mathrm{C} \%$ & $\mathrm{H} \%$ & N\% \\
\hline $\mathrm{L}$ & $\mathrm{C}_{16} \mathrm{H}_{12} \mathrm{~N}_{2} \mathrm{O}_{3}$ & $\begin{array}{l}\text { Yallow } \\
\text { red }\end{array}$ & 280 & 50 & $\begin{array}{l}68.9 \\
/ 66\end{array}$ & $\begin{array}{l}4.28 \\
15.9\end{array}$ & $\begin{array}{l}10.00 \\
/ 11.9\end{array}$ \\
\hline
\end{tabular}


TABLE II Analytical data, and molar conductance $\Lambda_{\mathrm{m}}$ for the divalent metal complexes with ligand $\mathrm{L}$

\begin{tabular}{|c|c|c|c|c|c|}
\hline \multirow[b]{3}{*}{ Complex } & \multirow[b]{3}{*}{ Empirical formula } & \multicolumn{2}{|l|}{ Elemental } & \multicolumn{2}{|c|}{ Analysis } \\
\hline & & \multicolumn{4}{|c|}{$\begin{array}{l}\text { Calcd./ } \\
\text { Found }\end{array}$} \\
\hline & & $\mathrm{C} \%$ & $\mathrm{H} \%$ & $\mathrm{~N} \%$ & $\Lambda_{\mathrm{m}}$ \\
\hline$\left[\mathrm{Mn}(\mathrm{L}) \cdot \mathrm{Cl} \cdot\left(\mathrm{H}_{2} \mathrm{O}\right)_{3}\right]$ & $\mathrm{C}_{16} \mathrm{O}_{6} \mathrm{~N}_{2} \mathrm{H}_{17} \mathrm{ClMn}$ & $\begin{array}{l}45.35 \\
145.30\end{array}$ & $\begin{array}{l}4.28 \\
12.09\end{array}$ & $\begin{array}{l}7.10 \\
18.88\end{array}$ & 9.3 \\
\hline$\left[\mathrm{Co}(\mathrm{L}) \cdot \mathrm{Cl} .\left(\mathrm{H}_{2} \mathrm{O}\right)_{3}\right]$ & $\mathrm{C}_{16} \mathrm{O}_{6} \mathrm{~N}_{2} \mathrm{H}_{17} \mathrm{ClCo}$ & $\begin{array}{l}45.30 \\
44 \cdot 30\end{array}$ & $\begin{array}{l}4.01 \\
/ 3.16\end{array}$ & $\begin{array}{r}7.50 \\
/\end{array}$ & 15.2 \\
\hline
\end{tabular}

TABLE III IR Frequencies and band assignments of the investigated ligand.

\begin{tabular}{ll}
\hline $\mathrm{L}$ & Band Assignment \\
\hline 3398 & $\mathrm{v}_{\mathrm{OH}}$ \\
3000 & $\mathrm{v}_{\mathrm{C}-\mathrm{H} \text { aromatic }}$ \\
1600 & $\mathrm{v}_{\mathrm{C}=\mathrm{O}}$ \\
1525 & $v_{\mathrm{C}=\mathrm{C}}$ \\
1450 & $\mathrm{v}_{\mathrm{N}=\mathrm{N}}$ \\
1268 & $\mathrm{v}_{\mathrm{C}-\mathrm{N}}$ \\
1168 & $\mathrm{v}_{\mathrm{C}-\mathrm{H}}$ \\
1066 & $\delta_{\mathrm{OH}}$ \\
899 & $\gamma_{\mathrm{C}-\mathrm{H}}$ \\
\hline
\end{tabular}

TABLE IV Frequencies and band assignment of ligand and its metal complexes $\left(\mathrm{cm}^{-1}\right)$

\begin{tabular}{lllllll}
\cline { 1 - 5 } Complex & \multicolumn{7}{c}{} & \multicolumn{1}{c}{} \\
\cline { 2 - 6 } & $v_{\mathrm{OH}}$ & $v_{\mathrm{C}=\mathrm{O}}$ & $v_{\mathrm{C}=\mathrm{C}}$ & $v_{\mathrm{N}=\mathrm{N}}$ & $v_{\mathrm{C}-\mathrm{O}}$ & $\gamma_{\mathrm{OH}}$ \\
\hline Mn-L(1:1) & 3598 & 1600 & 1605 & 1400 & 1199 & 799 \\
Co-L $(1: 1)$ & 3599 & 1683 & 1592 & 1386 & 1198 & 814 \\
Ni-L(1:1) & 3598 & 1673 & 1592 & 1398 & 1199 & 800 \\
Cu-L (1:1) & 3598 & 1679 & 1596 & 1382 & 1199 & 814 \\
Zn-L(1:1) & 3600 & 1681 & 1592 & 1382 & 1199 & 800 \\
\hline
\end{tabular}

TABLE V ${ }^{1} \mathrm{H}$ NMR spectral data of the investigated ligand and Ni complexes

\begin{tabular}{lll}
\hline Ligands and complexes & Chemical Shift $(\delta)$ & Assignment \\
\hline & 12.44 & OH proton \\
L & $7.42-7.39$ & Aromatic C-H protons \\
& 7.14 & Pyrone ring C-H \\
& 2.12 & $\mathrm{CH}_{3}$ pyrone ring \\
& & \\
Ni-L $(1: 1)$ & 7.53 & Aromatic C-H protons \\
& 7.14 & Pyrone ring C-H \\
& 2.90 & $\mathrm{H}_{2} \mathrm{O}$ of coordination \\
\end{tabular}




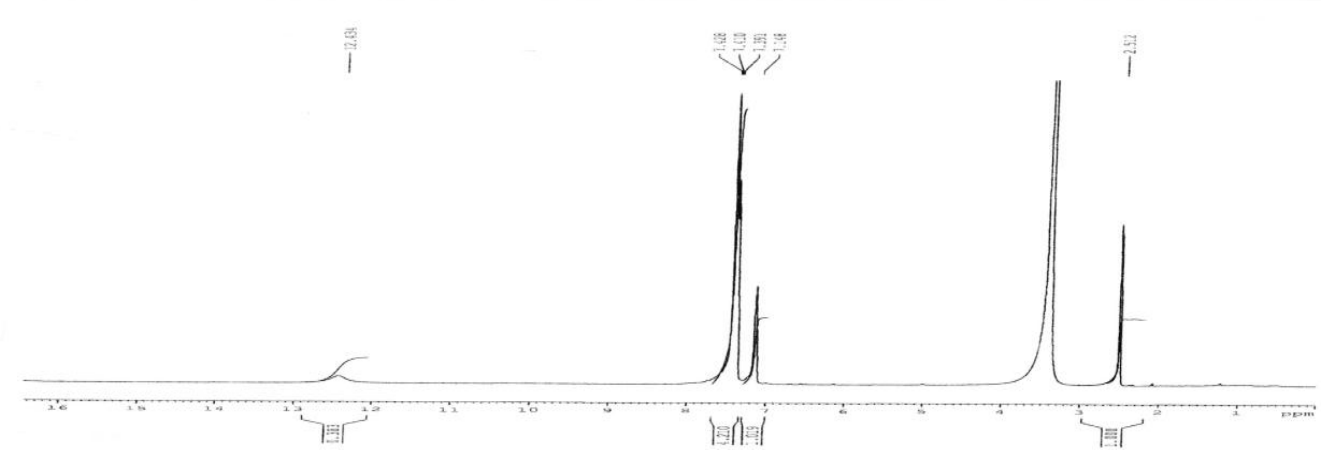

FIGURE (3) H NMR-spectra of ligand



FIGURE (4) HNMR-spectra of complex 